\title{
Desmascaramento do mundo colonial moçambicano em As visitas do Dr. Valdez, de João Paulo Borges Coelho
}

\author{
The unmasking of the Mozambican colonial world in As visitas do Dr. Valdez, \\ by João Paulo Borges Coelho
}

\author{
JOSÉ LUÍS GIOVANONI FORNOS \\ Universidade Federal do Rio Grande - Rio Grande - Rio Grande do Sul - Brasil
}

\begin{abstract}
Resumo: O presente trabalho investiga o romance As visitas do Dr. Valdez, de João Paulo Borges Coelho, considerando alguns conceitos de Mikhail Bakhtin. A obra traz múltiplos aspectos da vida colonial em Moçambique durante o século XX. Para reconstituir tal período, o autor recorre a diferentes estratagemas e categorias, dialogando com o passado e o presente através de um narrador onisciente. A violência cultural e política estão presentes através do mascaramento identitário. A noção de superioridade e inferioridade - cultural, econômica e racial - é a principal chave de leitura, uma vez que esta traduz a constituição do regime colonialista. Nesse sentido, o narrador expõe com precisão e rigor o funcionamento daquela estrutura, utilizando-se do recurso paródico-carnavalesco para discutir as questões da opressão colonial.
\end{abstract}

Palavras-chave: Romance moçambicano; História colonial; Riso paródico

\begin{abstract}
This study examines the novel As visitas do Dr. Valdez (The visits of Dr. Valdez), by João Paulo Borges Coelho, drawing on some concepts of Mikhail Bakhtin. The novel includes various aspects of colonial life in Mozambique during the twentieth century. In order to reconstruct this period, the author uses different schemes and categories by dialoguing with the past and present through an omniscient narrator. The cultural and political violence are present through the masking of identity. The notion of superiority and inferiority - cultural, racial and economic ones - is the main key to reading, since it reflects the establishment of colonialist regime. In this sense, the narrator exposes accurately and precisely the functioning of that structure, using the parodic-carnivalesque resource to discuss the issues of colonial oppression.
\end{abstract}

Keywords: Mozambique novel; Colonial History; Parodic laughter

Destaque na literatura moçambicana, o escritor João Paulo Borges Coelho nasceu em Portugal, na cidade do Porto. Filho de pai português e mãe moçambicana, desde cedo vive em Moçambique, naturalizando-se no país africano. ${ }^{1}$ Possui doutorado em História econômica e social pela Universidade de Bradford (Reino Unido) e licenciatura em História pela Universidade Mondlaine, em Maputo, exercendo atualmente o papel de professor

\footnotetext{
${ }_{1}$ Quando perguntado acerca de sua história pessoal, de sua identidade plural, já que nasceu em Portugal, João Paulo Borges Coelho confessa que a questão lhe causa desconforto. Não, segundo o autor, no sentido que seria de esperar, pois se sente bem na sua pele. Sua nacionalidade resulta mais de uma condição do que uma opção. O que pode dizer é que tem família há muitas gerações nos dois países e, dessa condição, lhe vieram os fios cruzados daquilo que designa de sentido de pertença física à terra, bem como de uma substância cultural da qual decorre uma visão do mundo. Assim, completa que "foi em Moçambique que tive consciência de pertencer fisicamente a uma terra, enquanto uma parte
}

e pesquisador nessa mesma universidade. Sua obra vem ganhando evidência através de inúmeros estudos e prêmios. Até o momento publicou seis romances, entremeados com livros de contos e novelas. ${ }^{2}$

Diante da formação profissional como historiador, João Paulo Borges Coelho é sempre questionado acerca dos laços entre história e ficção. Para o autor, há um limite claro acerca de cada um dos discursos, não se devendo

importante e não renegada da minha cultura é portuguesa." Para o autor, pluralidade é um ponto de partida, e não de chegada. Aponta que "isso não tem nada de extraordinário, uma vez que é cada vez mais comum pelo mundo todo, embora o continente africano seja ainda, infelizmente, mais um espaço de partida que de chegada."

2 Como ficcionista publicou as seguintes obras: As duas sombras do rio (2003); As visitas do Dr. Valdez (2004) Índicos indicios I. Setentrião (2005); Índicos indicios II Meridião. (2005); Crônica da Rua 513.2; Campo de trânsito (2007); Hinyambann (2008); O olho de Hertzog (2009), Cidade dos espelhos (2011) e Rainhas da noite (2013). 
confundi-los. Embora as fronteiras sejam tênues, a ficção não deve estar relacionada deliberadamente com a verdade. Segundo o escritor, "a literatura é invenção, chamar a uma história uma história verdadeira é um insulto tanto para a arte como para a verdade." Todavia, admite que haja traços da atividade de historiador na sua prática literária, em especial, no excessivo rigor na localização do espaço-tempo das tramas, assim como nas estruturas causais das explicações.

Os enredos de seus livros trazem sempre como pano de fundo a história de Moçambique, em especial, períodos de transição em que as tensões entre continuidade e mudança se fazem presente através da passagem, por exemplo, de episódios do colonialismo e da conquista da independência do país. Em tal percurso, as imbricações da identidade e os lugares estão presentes, trazendo à tona os conflitos de raça e etnia. Igualmente os contatos culturais que norteiam as relações coloniais figuram em seus textos, mostrando a força do poder político na configuração do espaço social. A memória é uma das mediadoras da relação entre passado e presente, tornandose elemento importante na constituição das personagens. É por meio dela que as expressões individuais e coletivas, não somente se entrelaçam, mas igualmente são problematizadas, ganhando peso estratégico à elaboração crítica ao sistema colonial. A memória, como assinala Paul Ricoeur, "continua a ser o guardião da última dialética constitutiva da preteridade do passado", isto é, a "relação entre o não mais que marca seu caráter acabado, abolido, ultrapassado, e o tendo-sido que designa seu caráter originário e, nesse sentido, indestrutível." (RICOEUR, 2007, p. 505)

O premiado romance As visitas do Dr. Valdez, encarna as proposições gerais acima, trazendo múltiplos aspectos da vida colonial em Moçambique. A partir das presenças europeia e portuguesa, entremeadas pelo olhar do nativo, o livro explora de forma original as relações de poder entre os diferentes segmentos sociais naquele território. A ocorrência dos embates se dá no meio rural e citadino, produtores do questionamento étnico-racial.

Os momentos de conflito entre o regime colonial português e os movimentos de libertação nacional cercam a trama. A narrativa apresenta uma crise, observada na ideia de que o velho está a agonizar enquanto o novo ainda não nasceu, como assinala Lukács acerca das tensões sociais. É um mundo que desaba, no dizer do narrador o que remonta à obra do escritor nigeriano Chinua Achebe.

Os episódios se deslocam continuamente, ora ecoando um presente marcado pela emergência clandestina da guerra e o desmoronar de uma família colonial, ora traduzindo o rememorar do tempo passado, revelador de episódios em que os contatos informam uma sociedade dividida por questões econômicas e de raça. Tal divisão desencadeia situações de violência, abandono e desilusão, regras de convivência assimiladas, em certas ocasiões, de forma contraditória.

Para dar conta dessa movimentação histórica que põe em xeque identidades e o poder colonial, o autor se utiliza, entre outras estratégias, do travestimento paródico que, segundo Bakhtin, insere correções permanentes de comicidade e de crítica na seriedade dos discursos sérios e elevados. ${ }^{3}$ Tal processo técnico-analítico e ideológico é conduzido através do diálogo entre as personagens, problematizando as noções de dependência e autonomia. De outro modo, ao introduzir tal proposição crítica, o autor não deixa de problematizar a própria estratégia empregada, enriquecendo o texto como artefato técnico e ideológico. Neste caso, a tática do destronamento através do recurso da paródia igualmente é interrogada, uma vez que os discursos empregados no deslocamento do poder ainda são insuficientes para derrubar as genealogias dos sujeitos focalizados. Nesse sentido, o desnudamento - momento da extração da máscara do Dr. Valdez pelo criado Vicente - implica no retorno às velhas hierarquias, asseguradas pela condição de classe e raça:

Quanto Vicente, desnudou-se. Vê agora - e é visto - sem intermediação da máscara-elmo nem de ninguém. Plantada no meio da sala, é quase ridícula a figura do rapaz. A roupa de Valdez, muito engomada, não condiz com o seu corpo franzino, não se enruga para deixar o registo dos seus movimentos. Traduzem, corpo e roupa, o desencontro que houve entre os dois, o criado e o fantasma. A cabeça pende-lhe ligeiramente para a frente, mal iluminada por uma expressão triste, muito menos agressiva do que Sá Caetana esperaria. Na mão uma máscara-elmo oca, também ela tendo perdido o vigor que manifestou enquanto encimava a cabeça de Valdez. O enigmático sorriso de madeira é agora um esgar imóvel de onde fugiu todo o desplante. Os olhos, dois buracos negros de onde escorreu toda a ameaça. Poderosa arma reduzida a inócuo objeto de artesanato. (COELHO, 2004, p. 166)

Para contar a história de servidão e violência entre o colonizador e o colonizado, entre brancos, mestiços e negros, João Paulo Borges Coelho recorre a um grupo familiar da elite em decadência da região da Ilha do Ibo, observando que a noção de superioridade cultural, econômica e racial era a chave no controle da sociedade

\footnotetext{
Inicialmente, as criações "paródicas-travestizantes" inserem correções permanentes de comicidade e de crítica na seriedade do discurso direto elevado, demonstrando que a realidade é mais contraditória e multilíngue do que pode conter as representações do gênero elevado. Disso resulta o significado atribuído ao plurilingüismo e ao dialogismo por Bakhtin, já que possibilitam liberdade e verossimilhança maiores à linguagem e sua representação. Para autor, "somente o plurilingüismo e o dialogismo libertam por completo a consciência do domínio da sua própria linguagem e do seu mito lingüístico".(BAKHTIN, 1998, p. 379.)
} 
colonial. Utiliza-se, para tanto, de um narrador onisciente cujo rigor e precisão na descrição dos acontecimentos que revela aspectos particulares do trabalho artístico do autor naquele ambiente de produção. A linguagem, marcada pela ironia, contenção e afeto, contrapõe-se ao clima hostil dos fatos, pondo em questão as relações de forma e conteúdo, reveladoras de uma posição conflitante entre o narrar e o narrado. ${ }^{4}$ Sem didatismo, o narrador assume, contudo, uma perspectiva crítica, mediada pela elegância linguística. Há uma tensão dialética, tradutora das dificuldades, incoerências e sentimentos dos sujeitos. Da dominação e obediência, acentuamse lacunas de intimidade, interpostas pelo preconceito e marginalidade histórico-cultural. Somam-se a estes aspectos pensamentos revoltosos abafados pelo terror do castigo e da fome. Penalidades que o autor reafirma, reproduzindo os efeitos das relações entre empregados e patrões no âmbito do colonialismo. Vale, nessa direção, acrescentar o testemunho de José Luís Cabaço, extraído do seu excelente estudo acerca do universo moçambicano. Segundo o estudioso:

Em Moçambique, até os primeiros anos da década de 1960, era corrente que os 'patrões' aplicassem punições físicas aos seus empregados domésticos (os 'criados') ou que as donas de casa portuguesas, perante um erro, infração ou desobediência de um 'criado', o enviassem à administração ou à estação de polícia com um bilhete no qual explicavam o delito e solicitavam punição física ou mesmo 'dias de calabouço'. O empregado punido devia devolver o bilhete à 'patroa' com um apontamento do funcionário informando que o castigo fora aplicado. (CABAÇO, 2009, p. 45)

Em outra passagem, Cabaço recorda a história da bofetada que recebera na infância reveladora do poder disciplinar estabelecido por um imaginário social interdito:

Tinha 13 anos e frequentava a que então era a única escola oficial de Moçambique, o Liceu Salazar, na cidade capital. Morava longe e ia de bicicleta às aulas. Uma manhã, ainda distante do Liceu, vejo um colega - um dos três colegas negros - correndo, porque se havia atrasado. Ofereci-lhe uma boleia na bicicleta.

\footnotetext{
4 Embora tal problematização seja própria da produção literária, no espaço africano ela ganha realce à medida que o escritor se depara com uma forte sociedade de prolongada origem oral em que múltiplos elementos culturais e linguísticos estão envolvidos. Além desse aspecto, há o efeito da crise ideológica que demarca a natureza e o papel dos intelectuais (escritores) em sociedades informatizadas, mediadas pela imagem. Assim, é sempre difícil para o escritor que, forjado à luz de categorias europeias e ocidentais, empreender uma dicção em relação a um espaço tão distintivo.

5 Segundo José Luís Cabaço, Rafael Arcanjo era "um jovem de 27 anos, de estatura mediana, forte de compleição, a pele bem escura, os ombros largos e um rosto redondo e sisudo."
}

Quando regressei das aulas, o familiar em casa de quem eu vivia recebeu-me com uma punição. Alguém lhe tinha telefonado informando que eu carregara na minha bicicleta um negro o que, não sendo ilegal, constituía uma violação dos códigos de autodefesa dos colonos. (CABAÇO, 2009, p. 47)

Em outro momento, José Luís Cabaço conta a história do empregado Rafael Arcanjo ${ }^{5}$ que trabalhava em sua casa. Cabaço lembra que ambos partilhavam a paixão pelo futebol, torcendo pela mesma equipe. Já inserido em um processo que o levaria a afirmar-se como moçambicano, aliando-se aos grupos que lutavam pela independência, o autor procura romper as barreiras, convidando Rafael para assistir a um jogo. No depoimento, Cabaço relembra:

Quando comprei os ingressos, ele [Rafael, o empregado] não me quis acompanhar na bancada dos 'civilizados'. Ele sabia que, na minha companhia, poderia sentar-se naqueles lugares, mas preferiu a bancada dos 'indígenas', do outro lado do estádio. 'Então vamos os dois para lá, disse eu. Rafael olhoume assustado e percebi que me implorava que o não fizesse. Fiquei muito perturbado, mas contrariá-lo seria uma posição arrogante e autoritária da minha parte e, provavelmente, o fim de uma possível amizade. No fim do jogo, voltamos a encontrar-nos para regressarmos a casa e só comentamos a partida. (CABAÇO, 2009, p. 134)

A trajetória em torno de Rafael Arcanjo continua a ser informada pelo estudioso que, percebendo o gosto pela fofoca do empregado, faz as seguintes observações acerca do comportamento do amigo:

Na relação doméstica, o ‘criado' era 'invisível' aos olhos dos colonos; fazia parte da casa como paredes e o mobiliário. As conversas dos 'patrões', e seus comportamentos decorriam sem quaisquer inibições perante aquele 'objeto' que, sendo parte do ambiente, deslizava silenciosamente entre membros da família realizando as tarefas da casa. Através de seus colegas, Rafael sabia (e contava obviamente sobre a casa onde trabalhava) da vida de cada vizinho, dos hábitos de todos eles, de quem maltratava os empregados, dos patrões que insultavam e até batiam nas mulheres. Até casos de infidelidade conjugal no bairro Rafael relatava entre gostosas gargalhadas de ambos. $\mathrm{O}$ tema criou cumplicidade entre nós. Eu sentia-me entrando num novo mundo, que sempre estivera ali sob meus olhos e que eu nunca fora capaz de ver. (CABAÇO, 2009, p. 135)

Tais observações reaparecem, em parte, de forma original no romance de João Paulo Borges Coelho. Entre elas, está a presença da categoria do olhar, importante projeção simbólica de poder social. A "aproximação" 
pelo olhar que caracteriza o quadro das ações, define os espaços de poder. A dimensão dos olhares constitui-se em um dos pontos eficazes da narrativa de João Paulo, expressa nos temores e anseios das personagens. ${ }^{6}$

O olhar. Talvez estivesse no olhar esse prazer que procurava. No intercâmbio de olhares entre uns e outros. Quantas vezes Cosme Paulino não conseguiu suportar o olhar azul-gelado de njungo Araújo e teve que baixar o seu! Outra vez os olhos. O olhar. Vicente imagina o olhar de Sá Caetana nesses tempos de concreta autoridade. Altivo, paralelo às copas dos coqueiros, raras vezes se cruzando com o olhar de seu pai que o tinha sempre passeando pelo chão, atento aos pequenos detalhes, tímido bicho rastejante. Raras vezes os dois olhares se encontravam, tão diferentes eram os respectivos caminhos. Mas no momento mágico em que tal acontecia traduzia-se toda a história daquele lugar. Sá Caetana agradecendo o favor feito, Cosme Paulino agradecendo o favor que ele próprio lhe fazia. Tudo isso resumido nesse encontro de olhares que tornava desnecessárias as palavras. (COELHO, 2004, p. 157)

O romance As visitas do Dr. Valdez erige-se a partir do presente, centrando-se na vida das irmãs Amélia e Caetana, e o criado Vicente. Vivem, agora, na cidade, protagonizando os suspiros finais de uma época. Recordam situações de infância que carregam as marcas da desigualdade e o recalcamento das relações familiares, mas também informa afetivas convivências subterraneamente arranjadas.

Dentre as recordações aparece Cosme Paulino, pai de Vicente, que acompanhara as irmãs desde o nascimento das mesmas. Representa o espaço dos colonizados, assumindo seu papel com dedicação e resignação extremas. Transforma-se em vítima tanto da violência colonial como também da resistência anti-colonial. Mantém até a morte, uma fidelidade exemplar, enviando notícias, através de cartas escritas por um primo, acerca da situação das terras após a saída das duas velhas senhoras. O retrato da casa grande e pequena, somado ao coqueiral, informa a economia da região e os ganhos de uma burguesia parasitária, vivendo à custa dos contratos de trabalho que fazem lembrar ainda a escravidão.

Um dos episódios estruturadores que dá título ao livro são as visitas do Dr. Valdez. O termo visita deve ser

\footnotetext{
6 Para o desenvolvimento de tal proposição, é fundamental a consulta da obra de Frantz Fanon. Numa passagem do livro Pele negra, máscaras brancas, Fanon explicita as dificuldades do colonizado em constituirse como pessoa diante da figura do homem branco: "Depois tivemos de enfrentar o olhar branco. Um peso inusitado nos oprimiu. $\mathrm{O}$ mundo verdadeiro invadia nosso pedaç. No mundo branco, o homem de cor encontra dificuldades na elaboração de seu esquema corporal. O conhecimento do corpo é unicamente uma atividade de negação. É um conhecimento em terceira pessoa. Em torno do corpo reina uma atmosfera densa de incertezas." (FANON, 2008, p.104)
}

lido com ironia, uma vez que se trata de uma inserção do sujeito inferior num espaço que lhe é proibido. A cortesia e a intimidade que geralmente estão associadas à palavra não se coadunam à condição da personagem Vicente. $\mathrm{O}$ episódio pode ser relacionado a um trecho do romance de E. M. Forster, comentado por Edward Said quando este discute os encontros entre ingleses e indianos:

Eu nunca tive notícia de qualquer resultado que não seja catastrófico quando ingleses e os indianos tentam ser íntimos socialmente. Contato, sim. Cortesia, sempre. Intimidade - nunca, nunca." (SAID, 1999, p. 257)

$\mathrm{Na}$ verdade, as visitas são as ocasiões em que o criado Vicente traveste-se de um médico de nome Valdez que vivera nas décadas de 1940 e 1950 em Moçambique, vindo a falecer em 1959. Vicente mascara-se de médico para atenuar as crises de Amélia. Presa a uma cadeira de rodas, a velha senhora manifesta-se, confessando à irmã a falta que sente do médico. De inocente brincadeira, o mascaramento ganha em proporção, à medida que o criado, agora na voz do médico branco português, passa a representar as interrogações acerca das relações de poder sedimentadas desde sempre entre empregados e patrões. Temerosa com as crescentes ousadias do rapaz, Caetana decide acabar com a farsa. Entre as ousadias, está o assobiar pelos aposentos, o sentar no sofá da sala a espera do chá, bem como, numa tarde quente, o criado, provocativamente, solicita uma cerveja gelada.

Todavia, Amélia, ainda que em processo total de degeneração física, questiona a ausência do referido médico, solicitando à irmã a presença do doutor. A morte de Amélia encerra o drama burlesco, aliviando a consciência de Caetana e Vicente. Depois do jogo, ambos jamais serão os mesmos, provocando um amadurecimento no jovem criado e uma reavaliação do ser em Caetana. A farsa possui um sentido educativo, projetando sonhos, desejos e lamentos.

Com base nesse episódio, é possível reavaliar as proposições de Bakhtin acerca da temática da carnavalização paródica quando o estudioso russo discorre sobre as funções do trapaceiro, do bufão e do bobo na literatura paródica medieval. $\mathrm{Na}$ visão de Bakhtin, tais figuras criam em volta de si microcosmos e cronotopos especiais, pois tudo "o que fazem e dizem não tem sentido direto e imediato, mas sim figurado e, às vezes, invertido." (p. 275) Assim parece ser o papel exercido pela personagem Vicente no romance quando passa a representar o médico português Valdez. Igualmente podem-se aproximar os atos da personagem a que Homi Bhabha denomina de o "incalculável sujeito colonizado", isto é, um sujeito "semi-aquiesciente, semi- 
opositor, jamais confiável" (BHABHA, 1998, p. 62) que promove a subversão dos poderes coloniais instituídos.

Ao criado Vicente, na infância, impressionava-o os trajes e trejeitos do doutor. Adulto, servindo às irmãs Sá Caetana e Sá Amélia, passa a imitar o médico, fato que se constitui numa eficiente estratégia adotada pelo escritor moçambicano João Paulo Borges Coelho para tratar das relações de poder no espaço colonial africano de língua portuguesa. Cabe aqui o comentário de Bakhtin: "o romancista precisa de alguma espécie de máscara consistente na forma e no gênero que determine tanto a sua posição para ver a vida como também a posição para tornar pública essa vida.” (p.277).

Nos diálogos com as senhoras, Vicente, travestido de médico, aproveita para encenar palavras e gestos que problematizam o caráter perverso e autoritário do colonialismo. O disfarce oportuniza o questionamento da autoridade e sua legitimidade social. Vicente, todavia, reconhece as limitações da estratégia. Sem tal mascaramento, corpo e palavra acolhem outra vez o estigma da inferioridade, assinalados pela vergonha e medo. Ainda que espaço e objetos estejam contaminados por outro dizer e tocar, o caráter subversivo daquela máscara é insuficiente para romper com o estado de coisas. $\mathrm{O}$ atrevimento de Vicente cresce quando, ao visitar as irmãs, traveste-se originalmente, agora, com uma máscara pertencente à sua etnia maconde. ${ }^{7}$

Assim, Vicente autoriza-se a ver o mundo às avessas, destronando a dominação colonial. A carnavalização do corpo se dá quando, a fim de metamorfosear-se no médico branco, Vicente utiliza-se de pedaços de algodão, numa "transfiguração racial" que os companheiros Jeremias e Sabonente, apoiadores da resistência e oposição ao regime, logo a classificam como ridícula.

Tal dramaturgia do ser colonizado em colonizador para pôr em xeque as estruturas de poder, na visão dos dois revoltosos, não possui alcance transformador, tratando-se somente de um chiste que depõe contra a identidade do sujeito oprimido. O palco da rua (o meio rural) - os acontecimentos da guerrilha proporcionados pelos movimentos de libertação nacional - é contraposto ao palco da sala da casa colonial, agora já reduzida num pequeno apartamento citadino. Assim, os limites da voz são evidentes, pondo em questão a independência identitária quando da não abolição da desigualdade material e da inferioridade racial em sua extensão geográfica e cultural.

Dessa forma, se a máscara funciona inicialmente em modo sutil para desmascarar o mundo colonial, ela revela igualmente restrições, podendo cair no pastiche ou no idealismo, protegido pela forma artística de um período. A ambivalência como promessa destronante

\footnotetext{
7 Máscara de Mapico, pertencente aos homens da etnia Maconde.
}

da ordem social pode ocasionar imobilismo, servindo apenas à catarse de uma classe. É nessa direção que as personagens Sabonete e Jeremias recusam a brincadeira do colega, insinuando que o mesmo trai sua condição étnico-racial e de classe. Um contexto novo permite-lhes a avaliação, já que os combates dos grupos de libertação nacional e o exército português são aludidos, passando a nortear as mudanças de comportamento das personagens. Se antes, tínhamos um mundo cristalizado numa longa tradição de obediência, ancorada nas formas de violência naturalizada, agora nos finais dos anos 1960 e início dos anos 1970, a instabilidade e o medo tomam conta daquele espaço.

É nesse sentido que nas páginas iniciais do livro, a personagem Amélia diz à irmã quando da chegada à Beira, ter muito medo. Amélia pressente que os longos anos vividos nas terras da família estão por serem abolidos:

- Caetana, tenho medo - articulou a primeira num sussurro. Desde que o mundo começou a desabar, dentro do seu corpo e fora dele, em redor, que diz aquilo como quem recita uma ladainha. É medo daquilo que não entende, do mundo que desaba. (p.10)

O comentário refere-se, como se disse anteriormente, ao mundo colonial que se despedaça, manifesto na alegoria da degeneração física de Amélia e na partida para Portugal de Caetana, assim como na crescente intervenção dos movimentos de libertação nacional, expressos nas vozes de Jeremias e Sabonente. Outro elemento importante de instrumentalização da consciência cultural e política é a presença de um aparelho de rádio de onde provavelmente os dois jovens capturam os ecos da guerrilha advindos do interior do país. Também estes insinuam as dificuldades internas em direção a uma coesão identitária, mostrando, numa dimensão prévia, do que será Moçambique após a independência do país.

O livro encerra-se com a despedida de Caetena e Vicente no aeroporto, marcada pela emoção controlada em que a multiplicidade da natureza das relações humanas pode ensejar distintos ordenamentos simbólicos e políticos. Os resultados são os mais diversos, desde a proliferação do elemento mítico das despedidas e deslocamentos, passando por resoluções individuais, alcançando, em última instância, uma reflexividade histórica que o tempo presente muitas vezes nos impede de uma avaliação mais precisa das estruturas profundas.

Aqui, o discurso romanesco aparece como a forma mediadora capaz de interrogar sujeitos e estruturas. Ao capitalizar as unidades narrativas internas, problematizando-as com a história do modo de produção colonial, o romance, em toda sua capacidade plástica, dá demonstração de sua força dialética. Os diálogos entre 
Vicente-Valdez e Caetana traduzem, simultaneamente, os limites e os avanços das configurações identitárias, alegorizando os entraves do gênero e autoria.

Se o romance As visitas do Dr. Valdez põe em questão de forma exemplar o colonialismo, expondo sua máquina atroz e desigual, ao mesmo tempo, problematiza as posições polarizadas e fixas, mostrando um cotidiano de fendas afetivas, bem como a coroação de lugares de memória e ritos culturais variados que tornam mais complexas as dimensões da ideologia e da história. Nesse sentido, o escritor moçambicano parece apontar "para a necessidade de relermos a sociedade de seu país como fruto de um largo processo de formação." (JORGE, p.135) Formação esta, a nosso ver, que não pode prescindir das trocas culturais advindas da convivência de vários povos e etnias, ainda que, num determinado período, a exploração e violência foram os paradigmas norteadores das relações humanas.

\section{Referências}

BHABHA, Homi. O local da cultura. Belo Horizonte: UFMG, 1998.
BAKHTIN, Mikhail. Questões de estética e de literatura. São Paulo: Hucitec, 1998.

CABAÇO, José Luís. Moçambique: identidade, colonialismo e libertação. São Paulo: Unesp, 2009.

COELHO, João Paulo Borges. As visitas do Dr. Valdez. Lisboa: Caminho, 2004.

FANON, F. Pele negra, máscaras brancas. Salvador: EDUFBA, 2008.

JORGE, Ś́lvio Renato. Para ampliar o campo do debate: releituras do colonialismo português em João Paulo Borges Coelho e outros autores. Revista Via Atlântica: estudos comparados de literatura de língua portuguesa, n. 16, 2009.

RICOEUR, Paul. A memória, a história, o esquecimento. Campinas; SP: Unicamp, 2007.

SAID, Edward. Cultura e imperialismo. São Paulo: Companhia das Letras, 1999.

SECCO, Carmen Tindó. Metamorfoses: Revista da Cátedra Jorge de Senna para Estudos Literários Luso-Afro-Brasileiros da Faculdade de Letras da Universidade Federal do Rio de Janeiro. (UFRJ), v. 10, n. 1, 2010.

Recebido: 30 de abril 2014 Aprovado: 12 de setembro 2014 Contato: jlgf@vetorial.net 